\title{
DE INTEROCEANISCHE VERBINDING VOOR 100 JAAR \\ DOOR
}

C. K. KESLER

In het jaar 1909 hield de heer H. P. de Vries, destijds agent der K. W. I. M. op Curaçao, een lezing voor de leden der Groep Ned. Antillen van het Algemeen Nederlandsch Verbond over het belang, dat de verbinding van den Atlantischen met den Stillen Oceaan voor de kolonie zou kunnen hebben. De verwachting, dat de opening van het Panama-kanaal op den opbloei van Curaçao een gunstigen invloed zou hebben, was toen bij de belanghebbenden vrij hoog gespannen. De spreker, die geacht kon worden in deze materie bij uitstek deskundig te zijn, toonde echter met cijfers aan, dat, al was ongetwijfeld wel voor $\mathrm{Cu}-$ raçao wat te verwachten van de aanstaande interoceanische verbinding, men toch goed zou doen, niet uit het oog te verliezen, dat verschillende omstandigheden het niet waarschijnlijk maakten, dat stoomvaartlijnen, die reeds gewend waren aan de verbinding met het Oosten via het Suez-kanaal, de koers harer schepen naar het westen zouden verleggen, terwijl bovendien, al geschiedde dit ook, Curaçao toch te ver bezuiden de route lag, die dan gevolgd zou moeten worden, om met St. Thomas, dat gunstiger gelegen is en een even goede natuurlijke haven heeft, als Curaçao, met succes te kunnen concurreeren. Over het geheel heeft tot dusver de uitkomst den spreker gelijk gegeven; Curaçao beleeft tegenwoordig een periode van bloei na lange jaren van malaise, de levendiger scheepvaart in de omringende zeeën ten gevolge van de opening van het Panama-kanaal zal daartoe wel eenigszins medegewerkt hebben, maar een hoofdstation op de lijnen, die West- 


\section{INTEROCEANISCHE VERBINDING VÓÓR 100 JAAR}

Europa met het Oosten verbinden, is het toch niet geworden.

Was dus de a.s. opening der verbinding tusschen de beide Oceanen toen de onmiddellijke aanleiding, dat men op Curaçao hoopte op nieuwen bloei door de verbinding van Oost en West, reeds veel vroeger had men het oog op dat eiland gevestigd als een hoofd-basis voor het interoceanische verkeer en in de maand Juli van dit jaar, zal het juist een eeuw geleden zijn, dat van Nederlandsche zijde daartoe ernstige plannen gemaakt werden, die echter weldra als onuitvoerbaar ter zijde moesten gelegd worden. Bij gelegenheid van de op handen zijnde openstelling van het Panama-kanaal verscheen in het laatst van het jaar 1912 in de N. R. C. een feuilleton, waarin Mr. Th. Heyligers een en ander mededeelde omtrent bovengenoemde plannen. Zij betroffen niet de verbinding der beide Oceanen door de doorgraving van de landengte van Panama, maar richt ten het oog op die van Nicaragua, die reeds eeuwen geleden, eigenlijk reeds kort na de ontdekking van Amerika, de aandacht getrokken had, als een geschikt punt voor het graven van een kanaal, toen het duidelijk begon te worden, dat de gewenschte doorvaart, die men zoowel in Noord-, als in Zuid-Amerika met volharding gezocht had, niet bestond, Twee omstandigheden waren er, die maakten, dat juist toen, bij het begin van de 19e eeuw Neder, land zich er bijzonder voor interesseerde; in de eerste plaats, dat Koning Willem I, de Souverein-koopman, een open oog had voor alles, wat strekken kon, om den tijdens den Franschen tijd zoozeer vervallen handel van het nieuwe koninkrijk er weer boven op te brengen, en in de tweede plaats de opstand der Spaansche koloniën tegen haar moederland, waardoor in Zuid- en Midden-Amerika een geheel veranderde staat van zaken intrad. Naast Souverein was Willem I ook handelsman; het belangrijke aandeel, dat hij had in de oprichting van de Nederlandsche Handelmaatschappij en de zending van Van den Bosch naar Oost-Indië, die de invoering van het Cultuurstelsel daar ten gevolge had, zijn voldoende bekend. Van minder algemeene bekendheid is het wellicht, dat de Koning voor 
de West nog grootschere plannen had en, toen een schijn van verwezenlijking zich opdeed, hij de gelegenheid daartoe met beide handen aangreep, doch haar even spoedig weer losliet, toen zijn scherp doorzicht in commercieele aangelegenheden hem aangetoond had, dat de plannen niet meer dan zeepbellen waren.

In 1816 kwamen zooals bekend is, de meeste onzer koloniën, die in Engelsche handen waren, weer aan het Moederland terug. Zoo heel gemakkelijk was dat niet gegaan. Ceylon en de Kaap behield Engeland, de laatste ,as a position connected with the security of our (d.w.z. het Britsche) Empire in the East"; Java had Raffles ook gaarne willen behouden en van teruggave van onze Westindische koloniën was aanvankelijk in het geheel geen sprake, omdat de Britsche Minister van Buitenlandsche Zaken, deze beschouwde als alleen van belang voor den handel „purely commercial" dus niet voor oorlogsdoeleinden en als middel om Nederland sterker te maken tegenover Frankrijk. De onderhandelingen over de teruggave werden lang niet altijd op vriendschappelijken voet gevoerd; tegenover de meening van Lord Castlereigh, die op grond der verovering verklaarde: „C'est à nous de juger ce qu'il faut rendre ou garder", stelde Willem I zijne beschouwing, dat het jonge koninkrijk zich niet kon neerleggen bij „l'abandon de nos meilleures colonies". Ten slotte dreef de Koning gedeeltelijk zijn zin door, wat de West betreft. Met uitzondering van Essequibo, Demerara en Berbice werd deze teruggegeven; de Nederlandsche regeering legde zich bij den afstand dezer drie koloniën neer en het verdrag werd onderteekend door Falck, destijds gezant te Londen, tot groote ergernis van den Minister van Buitenlandsche Zaken, Van Nagell van Ampsen, die van meening was, dat bij langer aanhouden van onze zijde, ook deze koloniën weer onder het Nederlandsche gezag hadden kunnen terugkeeren.

Voor de nu terugverworven Westindische koloniën trachtte Willem I het noodige te doen, om ze weer tot bloei te brengen. Daartoe zou op het voorbeeld van de in 1824 voor Oost-Indië gestichte Handelmaatschappij een 
Amerikaansche Compagnie gesticht werden met een kapitaal van $f 5.000 .000$, waarvan de Koning zelf $f 2.000 .000$ voor zijne rekening zou nemen. De zetel der nieuwe Compagnie zou te Amsterdam zijn, terwijl Curaçao als hoofddepot voor den handel in het Westen uitgekozen werd. Een kanaal door een der landengten, van Midden-Amerika, waardoor ook de Westkust in de zakensfeer der Compagnie zou kunnen worden betrokken, zou deze natuurlijk ten zeerste ten goede komen. Het graven van zulk een kanaal was reeds een zeer oud plan, zooals boven gezegd werd, dat telkens weer opgevat en even dikwijls weer losgelaten werd. Reeds zeer kort na de ontdekking van Nicaragua door Gil Gonzalez Davilo in 1522, die van Panama was uitgezeild om de "Specerij-eilanden" te zoeken, en op zijn reis aan de Westkust van MiddenAmerika landde, was bij dezen in verband met berichten, die hij kreeg omtrent de gesteldheid van het binnenland, de gedachte opgekomen, de Noordzee (d.w.z. de Caraibische Zee) met de Zuidzee door middel van een kanaal te verbinden, nu het hoe langer hoe duidelijker werd, dat een doorvaart, door de natuur gevormd, tusschen die twee zeeën niet bestond, althans niet in het den Spanjaarden bekende deel van de Nieuwe Wereld. Volgens zijn rapport was het tot stand brengen van zulk een kanaal geen zeer bezwaarlijk werk: slechts enkele mijlen vlak land zou men hebben door te graven. Hoewel reeds in het jaar 1528, toen de rivier San Juan en het meer van Nicaragua inmiddels beter bekend waren geworden, in Spanje ernstige plannen gemaakt werden, om tot verbinding van de beide Oceanen over te gaan, zou het toch nog drie eeuwen duren, eer daarmede een aanvang gemaakt werd. Een blik op de kaart van Midden-Amerika doet zien, dat al was de eerste opgave van enkele mijlen geheel vlak land niet geheel juist, de landengte van Nicaragua eigenlijk evenzeer door de natuur was aangewezen, om doorgegraven te worden als die van Panama. De rivier van San Juan toch, die bij het vroegere San Juan de, Norte (thans Greytown) in de Caraibische Zee uitmondt, wijst vanzelf den weg naar het meer van Nicaragua en van den Weste- 
INTEROCEANISCHE VERBINDING VÓÓR 100 JAAR 129

lijken oever hiervan bij San Carlos tot San Juan del Sur aan den Stillen Oceaan is de afstand niet grooter dan die van Colón naar Panama.

De veranderde omstandigheden, die ingetreden waren door den opstand der meeste Spaansche koloniën, hare erkenning door verschillende Europeesche mogendheden en door de Vereenigde Staten als onafhankelijke republieken en de plannen met de Westindische Koloniën, maakten, dat vooral bij den Koning veel belangstelling bestond voor het tot stand komen van eenig interoceanisch kanaal. Voorzichtigheid met eventueele bemoeiïngen daarmede was echter vooral voor het jonge koninkrijk geboden. Met verschillende Europeesche mogendheden waren moeilijkheden te vreezen, terwijl ook de Vereenigde Staten ontzien dienden te worden. Immers de beginselen van het Heilig Verbond duldden geen erkenning van opstandige koloniën als zelfstandige staten, en zoo noodig kon dit hun of hunnen bondgenooten ingescherpt worden door een of meer Europeesche mogendheden, die in de Groote Alliantie vereenigd, de rust in Europa handhaafden. Aan den anderen kant moest tegenover de Vereenigde Staten eenige voorzichtigheid in acht genomen worden, daar deze bemoeiïngen van Europeesche mogendheden met Amerikaansche aangelegenheden ongaarne zagen, wat reeds in 1823 door president Monroe in zijn bekende boodschap aan het Congres onder woorden gebracht was, terwijl bovendien de Vereenigde Staten zelf reeds stappen gedaan hadden, om op de eene af ondere wijze een belangrijk deel van de controle over een eventueele interoceanische verbinding voor zichzelf te verzekeren. Eindelijk waren de opstandelingen, hoe verheugd ook ontheven te zijn van de onderdrukking van Spanje, wat kort daarna in beeld gebracht werd in de kleuren van de Venezolaansche vlag, geel, blauw, rood, d.w.z. „het gouden Venezuela, gescheiden van het bloedige Spanje door de azuren zee," toch onderling alles behalve eensgezind.

Weinigen waren er onder hen, die inzagen, dat het afschudden van deSpaansche overheersching een ander doel behoorde te hebben dan, in plaats van de vroegere onder- 


\section{INTEROCEANISCHE VERBINDING VÓÓR 100 JAAR}

drukkers, zelf den baas te gaan spelen. Een dier weinigen was Simon Bolivar, die steeds met het voorbeeld der groote republiek in Noord-Amerika voor oogen, als ideaal de vorming van eene dergelijke unie der Latijnsche Amerikaansche staten koesterde. Reeds kort na het uitbreken van den eersten opstand tegen het Spaansche gezag in 1810 had hij daartoe pogingen gedaan; had, nadat hij van uit zijne toenmalige residentie Angostura in 1818 de vrijheid van de Zuid-Amerikaansche staten geproclameerd had, als antwoord op geruchten van interventie uit Europa ten behoeve van Spanje, daaraan toegevoegd de verklaring van de eenheid van Zuid-Amerika. Weliswaar was deze nog ver te zoeken, maar de Bevrijder werkte er steeds aan voort. Tegelijkertijd met bovengenoemde proclamatie van de vrijheid en eenheid van geheel Zuid-Amerika, zond hij eene uitnoodiging aan de Argentijnsche provinciën om in deze richting met hem samen te werken en wist na de verovering van Bogotà in 1819 eene unie tusschen Venezuela en Columbia tot stand te brengen. In 1825 - toen Bolivar inmiddels tot Dictator en Libertador ook van Peru en Columbia was uitgeroepen en zijn medestander, generaal Sucre als President van Bolivia had weten te doen verkiezen, trachtte hij zijn ideaal van de Unie van Latijnsch-Amerika te verwezenlijken door de bijeenroeping van een Pan-Amerikaansch Congres te Panamà. Oorspronkelijk bedoeld als eene samenkomst ter bespreking van de gemeenschappelijke belangen van de Zuid- en Middel-Amerikaansche republieken, werden op aanbeveling van de gezanten van Mexico, Columbia en Guatamala te Washington ook de Vereenigde Staten van NoordAmerika tot het zenden van een of meer gedelegeerden uitgenoodigd, terwijl kort daarna eene dergelijke uitnoodiging eveneens gericht werd tot verschillende Europeesche mogendheden, die belangen in Amerika hadden, o.a. ook tot Nederland. De in Panamà vertegenwoordigde republieken waren Peru, Columbia, Mexico en de toen nog Geconfedereerde Staten van Middel-Amerika, n.l. CostaRica, Guatamala, Honduras en San Salvador. Frankrijk en Spanje gaven aan de uitnoodiging natuurlijk geen ge- 
hoor, Engeland en de Vereenigde Staten wel. De gedelegeerden van de laatsten woonden echter het Congres niet bij, daar de eene op zijne reis daarheen stierf en de tweede zooveel oponthoud had, dat hij eerst na de sluiting der zittingen aankwam.

In Nederland werd naar een middenweg tusschen deelname en onthouding gezocht. Openlijk gehoor geven aan de ontvangen uitnoodiging was om de boven aangegeven redenen niet wenschelijk, zich geheel onthouden in verband met plannen voor den handel echter evenmin. Gelukkig kon toen Koning Willem I beschikken over iemand, aan wien hij meende de delicate zending naar MiddenAmerika met vertrouwen te kunnen opdragen, zulks op grond van ervaringen met hem opgedaan bij gelegenheid van eene vroegere zending naar de Westkust van Afrika, waar hij moest onderzoeken of er van de kolonie Delmina nog wat te maken was, b.v. als een centraal depot voor den slavenhandel en als een werfdepot voor neger-soldaten. Die vertrouwde man was de kolonel van den Generalen Staf Jan Verveer. Dezen werd in 1826 bij K. B. opgedragen zich naar West-Indië en Amerika té begeven, om te zien, wat daar in het belang van den Nederlandschen handel verkregen kon worden.

Via Curaçao begaf Verveer zich met zijn secretaris, den 1en luitenant M. Simon naar Chagres, om vandaar Panamà te bereiken. De weg over de landengte was in die dagen nog zeer moeilijk; bovendien was gebleken, dat de gele koorts de uitgekozen stad al zeer ongeschikt maakte voor het houden van een congres, waarom de zetel daarvan dan ook inmiddels verplaatst was naar Tabroja in Mexico. Den Nederlandschen gemachtigde bleef dus niets anders over, dan zich daarheen te begeven, maar voor zijne lastige reis werd hij al zeer slecht beloond, want het geheime karakter zijner zending werd hem zeer kwalijk genomen, als een bewijs van de vrees van den Koning om de republieken als zelfstandige mogendheden te erkennen Verveer moest dan ook constateeren, dat zijne zending als mislukt moest beschouwd worden en dat er niet veel kans op was, onder de gegeven omstandigheden voor den 
Nederlandschen handel iets te bereiken. Van zijne aanwezigheid op het congres werd echter gebruik gemaakt door den afgevaardigde van Guatamala om te trachten zijn steun te verkrijgen voor het plaatsen van eene leening van 7.000.000 peseta's in Nederland. Guatamala, de minst belangrijke der Spaansche bezittingen in Amerika was kort na de ontdekking en inbezitneming door Pedro de Alvaredo, een der onderbevelhebbers van Cortez in 1523 een afzonderlijk Kapitein-Generaalschap geworden en had zich 15 Juni 1821 van het moederland onafhankelijk verklaard. Voorloopig bleef de toestand in de nieuwe republiek, zooals hij onder het Spaansche bewind geweest was; de overige deelen van Centraal Amerika, als Honduras, Nicaragua, San Salvador en Costa Rica bleven met de hoofdrepubliek verbonden, doch vertoonden al spoedig neiging zich zelfstandig te organiseeren, wat tot onophoudelijke burgeroorlogen aanleiding af en in 1838 tot de definitieve afscheiding dezer staten van Guatamala leidde.

Verveer schreef over de voorgeslagen leening naar Holland, doch vond, gezien den onzekeren toestand in Midden-Amerika, geen vrijheid het voorstel krachtig te ondersteunen. Het resultaat zijner zending was dus voorloopig al heel poover en het is niet te verwonderen, dat Verveer gaarne de gelegenheid aangreep, toen zich vrij onverwacht de kans voordeed, althans iets te bereiken. Die kans werd geboden door het volgende. Met den Consul-generaal Haefkens te Guatamala had Verveer gecorrespondeerd over de mogelijkheid, daar een markt te vinden voor Hollandsche waren. In die correspondentie, waarvan hij afschriften naar Holland gezonden had, was o.a. sprake van de mislukking der plannen van zekeren Palmer met betrekking tot een kanaal door de landengte van Nicaragua, waarbij Verveer de opmerking gemaakt had, dat hier voor Hollandsche ingenieurs, goed bekend met het bouwen van sluizen en dergelijke werkzaamheden een goed veld van arbeid zou te vinden geweest zijn, De aandacht van Willem I, die te Brussel verblijf hield, toen deze correspondentie hem bereikte, viel op deze passage, waarom hij door den Secretaris van Staat aan den Minis- 
ter van Buitenlandsche Zaken in den Haag deed vragen, welk kanaal hier bedoeld werd, onder welke voorwaarden het totstandkomen ervan aan Hollandsche ingenieurs zou kunnen worden opgedragen ,welke kosten er vermoedelijk aan verbonden zouden zijn en welke inkomsten eventueel te verwachten zouden zijn. Deze vragen kreeg Verveer te beantwoorden, doch de missive van den Minister bereikte hen eerst te New-York, waarheen hij zich inmiddels op zijn terugreis naar Holland begeven had.

Allereerst moest hij nu trachten, in contact te komen met Palmer, waarbij het geluk hem eenigszins diende, want deze bleek juist te New-York te zijn, alleen niet zoo onmiddellijk te bereiken, daar hij in de gevangenis zat. Bedoelde Aaron Palmer, een Kwaker, was chef geweest van een handelshuis te New-York, doch had met allerlei tegenspoeden te kampen gehad. Door middel van een tusschenpersoon, een Pool, Boneski, had hij getracht, een contract te sluiten met de republiek Nicaragua voor het graven van een kanaal door de landengte en was, toen dat gelukt was, naar Engeland gegaan, hopende het contract te gelde te maken, om daarna orde op zijne verwarde zaken te kunnen stellen. Noch in Engeland, noch in de Vereenigde Staten gelukte het hem echter, er geld op los te krijgen, zoodat hij onverrichter zake naar New-York terugkeerde, waar hij vervolgens door zijne crediteuren gegijzeld werd. Een en ander vernam Verveer door bemiddeling van den Consul te New-York, Zimmerman en te Washington gelukte het hem daarna eenige verdere inlichtingen te krijgen omtrent de plannen ten opzichte van het geprojecteerde kanaal. In weerwil van de reeds ondervonden tegenspoeden en in weerwil van de omstandigheid, dat er op dat oogenblik eigenlijk nog geen republiek Nicaragua bestond, die in staat was een betrouwbaar contract af te sluiten, bleef Verveer steeds optimist en in zijn rapport omtrent de gedane stappen in het laatst van 1827 beval hij de Nederlandsche bemoeiïngen ermede zeer aan en adviseerde o.a. tot het zenden van een commissie van deskundigen, om door deze de zaak nader te doen onderzoeken. 


\section{INTEROCEANISCHE VERBINDING VÓÓR 100 JAAR}

Bij den Koning vielen Verveer's voorstellen in goede aarde; deze kreeg opdracht niet naar Nederland terug te keeren, maar zich opnieuw naar Midden-Amerika te begeven, terwijl overwogen werd, daarheen ook eenige genieofficieren te zenden, die destijds op Curaçao gedetacheerd waren voor de herstelling en verbetering der forten aldaar. Van deze zending kwam echter niets, want zooals bekend is, had Engeland bij de oprichting van het vergroote koninkrijk der Nederlanden als eisch gesteld de bouw van een reeks forten langs de grens van Frankrijk en daarvoor zelfs een belangrijk voorschot verleend. Deze forten nu, het Zuiderfrontier, waren door Wellington geinspecteerd en in onvoldoenden toestand bevonden, waarom genie-officieren in Holland zelf zeer noodig waren. De naar Curaçao gedetacheerden werden daarom teruggeroepen en voor Nicaragua werden alleen een paar civiele ingenieurs bestemd onder leiding van een luitenant van de genie, die echter voorloopig nog geen opdracht kregen af te reizen.

Nadat Verveer eenige maanden in Holland terug geweest was om persoonlijk besprekingen te houden, in de eerste plaats met den Koning over de grootsche plannen in de West, vertrok hij in Februari 1828 naar Havre, scheepte zich daar op de „Talma” naar New-York in en maakte van zijn kort verblijf aldaar gebruik om den President Adams voor de kanaalplannen te winnen. Ook bij dezen vielen Verveers voorstellen in zoo goede aarde, dat hij voor diens reis naar Midden-Amerika de Amerikaansche corvet „Erie”, aanbood. In Februari 1829 kwam Verveer in Guatamala aan, vergezeld van zijn particulieren secretaris Jhr. Bangeman Huygens. Daar was de toestand echter alles behalve geschikt om werken des vredes te gaan ondernemen; de strijd van Honduras en San Salvador tegen Guatamala was in vollen gang, de hoofdstad der laatste republiek werd kort na de aankomst der Nederlandsche gedelegeerden door de vijanden geplnuderd, waarbij Huygens zijne bagage verloor en de pogingen van Verveer, daarin bijgestaan door den Consul-generaal Haefkens, om den vrede tot stand te brengen, bleven 
vruchteloos. Verveer deed dan ook weldra door zijn secretaris een nota aan den Minister van Buitenlandsche $\mathrm{Za}$ ken richten, waarin hij zelf afried, voorloopig de commissie van ingenieurs te zenden.

$\mathrm{Na}$ eenige maanden bedaarde de storm in MiddenAmerika echter. Guatamala wist zich staande te houden tegen de aanvallers, geraakte door de goede maatregelen van generaal Morazon aanvankelijk zelfs in het voordeel en na een bal gegeven te hebben ter eere van Mevrouw Morazon en de vriendschap van den overwinnenden generaal, die inmiddels president van Guatamala geworden was, te hebben gewonnen, meende Verveer naar Holland te kunnen berichten, dat de toestand in Midden-Amerika nu zoodanig was, dat hij de zending der ingenieurs kon aanbevelen. Deze aanbeveling kwam echter op een zeer ongelegen tijd in Nederland aan. De moeilijkheden met België waren sedert 1828 steeds grooter geworden en al was de opstand nog niet uitgebroken, 's Konings aandacht was toch te veel voor het Zuiden vereischt, om te kunnen verwachten, dat er veel van voor het MiddenAmerikaansche kanalenplan zou overblijven. Bovendien was Verveers secretaris Jhr. Huyghens teruggekeerd en drong aan op eene schadevergoeding van $f 8.000$ voor zijne verloren bagage. Dit alles maakte, dat de Koning langzamerhand genoeg van het plan begon te krijgen en Verveer geruimen tijd vruchteloos op eenig definitief antwoord moest wachten. Op zijn beurt verdroot dat hem en na herhaaldelijk erop te hebben aangedrongen, dat er nu toch voortgang met de zaak gemaakt zou worden, sloeg hij ten slotte in zijne correspondentie zelfs een eenigszins dreigenden toon aan. Zoo iets nu viel volstrekt niet in den geest van Willem I, die al te groote zelfstandigheid in zijn dienaren niet kon velen, wat verschillende hunner, b.v. Van Hogendorp hadden moeten ondervinden. Verveer kreeg dan ook bericht, dat de door hem gewenschte commissie niet zou komen, doch hem werd opgedragen, onderhandelingen te openen met de verschillende regeeringen in Midden-Amerika over een conventie voor het graven van een kanaal door Nederland en over het sluiten 


\section{INTEROCEANISCHE VERBINDING VÓÓR 100 JAAR}

van een tractaat van vriendschap, scheepvaart en handel.

In Midden-Amerika had men wel ooren naar de nieuwe voorstellen en was bereid daartoe een contract te sluiten met Nederlandsche kapitalisten, doch gedachtig aan de ervaringen met Palmer opgedaan, alleen onder garantie van de Nederlandsche regeering. Het handelsverdrag werd voorloopig door Verveer gesloten voor den tijd van twee jaar, onder voorbehoud van definitieve goedkeuring ervan door zijne regeering. De consul-generaal Haefkens, die inmiddels naar Nederland vertrokken was, diende daar een rapport in omtrent den stand der onderhandelingen bij zijn vertrek en legde daarbij met betrekking tot de kanaalplannen, als bijlage alleen over een kaart van waterpassingen door de Spanjaarden verricht in 1786, dus niet bepaald up to date. Verveer zelf liet ondertusschen verder niets meer van zich hooren, waarom men in Nederland ongeduldig begon te worden, al was ook over het algemeen het vertrouwen daar omtrent de Midden-Amerikaansche kanaalplannen niet bijster groot. Trouwens, reeds voor het uitbreken van den Belgischen opstand was dat gering; in 1828 b.v. noemt Falk in een zijner brieven het „een avontuurlijk plan, om voor ons geld en met het talent van onze ingenieurs een doortocht te graven naar de Zuidzee". Ten slotte werd aan Verveer, die voorloopig nog geen plan scheen te hebben, terug te keeren, een soort ultimatum gezonden. Bij geheim K. B. van 20 Februari 1831 werd hem te kennen gegeven ,dat wissels van hem slechts gehonoreerd zouden worden tot 1 Juli 1831, ,zullende latere wissels met protest worden afgewezen". De gemachtigde was daardoor wel genoodzaakt, aan zijn verblijf in Midden-Amerika een einde te maken, wat hij dan ook in het begin van 1831 deed. Omstreeks Juli was hij in het moederland terug met leege handen, want het eenige, dat hij had kunnen verkrijgen, het voorloopige handelsverdrag, werd ten slotte door de regeering niet goedgekeurd. Zijn rapport omtrent de gevoerde onderhandelingen hield hij daarom ook maar achterwege en, nadat een verzoek zijnerzijds, om wederom bij het leger te worden 
ingedeeld, van de hand was gewezen, vestigde hij zich als ambteloos burger te Beverwijk.

Onzerzijds was de zaak dus afgeloopen; in MiddenAmerika dacht men er echter anders over. Nadat zich daar eenigszins geregelde toestanden gevestigd hadden, had men in Nicaragua na de afscheiding van Guatamala het kanalenplan nog eens ter hand genomen, en de grondslagen van een concessie daarvoor aan Nederland werden 20 December 1833 vastgesteld. Nederland liet echter niets meer van zich hooren en de nieuw gevormde republiek beschikte niet over geldmiddelen, maar had wel genoeg schuldeischers. In het belang der laatsten was het natuurlijk, dat de zaak van het kanaal niet geheel werd opgeborgen, uitvoering ervan gaf hun althans eenige kans iets van hun geld terug te zien. Een dergenen, die een vordering op de republiek hadden, was een Fransche koopman, Mercher, wien uitzicht op betaling geopend werd, zoodra de overeenkomst met Nederland gesloten zou zijn. Om ,de zaak een weinig te activeeren”, zooals Falck schrijft, begaf Mercher zich daarom naar Holland en zocht allereerst Verveer te Beverwijk op. Deze kon hem echter weinig hoop geven; zijn eigen invloed was allergeringst en bovendien kostte de Belgische opstand zooveel, dat men in Holland aan het uitvoeren van groote werken in het land zelf niet eens kon denken. De inschrijving voor den aanleg van een spoorweg van Amsterdam naar Keulen b.v. was kort geleden mislukt. Mercher gaf echter den moed niet zoo onmiddellijk op en ging bij den Koning op audientie, wat ten gevolge had, dat aan Verveer opgedragen werd, alsnog een rapport omtrent zijne bemoeiingen in Midden-Amerika in te dienen. Dit rapport werd aan den Minister van Koloniën en aan den Directeur-Generaal der Marine om advies gezonden. Beider oordeel luidde ongunstig, vooral dat van den Minister van Koloniën Van den Bosch, die West-Indië door zijn verblijf daar in 1828 uit eigen aanschouwing kende. Had de Directeur-Generaal der Marine alleen gewezen op de duurte van het plan en op het onpractische ervan in verband met wind en stroomen, het oordeel van Van den Bosch was eenvoudig 
vernietigend. Vooropstellende, dat negers en Indianen te lui waren om te werken, wees hij er vervolgens op, dat Europeesche werkkrachten gebruikt zouden moeten worden, wat wegens het klimaat niet mogelijk was. Daarom zou er geen industrie kunnen ontstaan, zoodat naar zijn oordeel de Midden-Amerikaansche streken even onbeduidend zouden blijven, als de West- en de Oostkust van Afrika. Hierom en in verband met de veranderde omstandigheden in Nederland adviseerde hij dan ook tot terugtrekken. Hiertoe werd in de eerste helft van 1835 besloten. Ondertusschen had Mercher geruimen tijd, wachtende op de beslissing, in Den Haag verblijf gehouden. Zeer teleurgesteld door de afwijzende beslissing, beklaagde hij er zich bitter over, zoo lang nutteloos opgehouden te zijn en drong ook al aan op vergoeding van de door hem gemaakte kosten.

Met het aandeel van ons land in het tot stand komen der interoceanische verbinding was het dus uit; ook de door den Koning gewenschte Amerikaansche Compagnie kwam niet tot stand en zoo sluimerde de belangstelling voor de West, eenmaal in de schatting des Konings „nos meilleures colonies" langzamerhand in. Van de zijde van Nicaragua werd in 1844 nog eens een poging gewaagd, de zaak van het kanaal nieuw leven in te blazen. De toenmalige gezant van dat land te Brussel, (Nicaragua was evenals de overige staten van Midden-Amerika in 1838 als onafhankelijk erkend) sprak er n.l. over met zijn Nederlandschen ambtgenoot, waarna Koning Willem II advies van den Minister Van Hall vroeg. Hoe dit uitgevallen is, is niet bekend, maar in verband met den toestand der financiën is het niet twijfelachtig, dat Van Hall ongunstig geadviseerd heeft.

Trouwens, hoewel het uiterst jammer is, dat de Nederlandsche invloed zich daar niet heeft kunnen vestigen, te verwachten was het, dat die er toch niet blijvend zou geweest zijn. Tusschen 1830 en 1840 toch had zich door verschillende omstandigheden een levendige belangstelling in de Vereenigde Staten voor het Westen ontwikkeld. Na de vastelling van de N. W. grens was Oregon bij de Unie 
gevoegd, terwijl na het beëindigen van den oorlog met Mexico Californië als nieuwe staat in de Unie werd opgenomen, waar in 1848 goud ontdekt werd, wat een stroom van avonturiers daarheen lokte. „The Far West”, tot dusver vrijwel zonder eenig belang, trok daardoor plotseling de algemeene aandacht en als gevolg daarvan ontwaakte een nieuwe belangstelling in de Unie voor de verbinding der beide Oceanen. Zooals bekend is, kwam die ten slotte niet via de landengte van Tehuantepec, noch via Guatamala, noch ook via Nicaragua, maar door de landengte van Panama tot stand.

Amsterdam, Maart 1926. 